\title{
TRENDS AND SOCIAL IMPLICATIONS OF RESEARCH ${ }^{1}$
}

\author{
BY R. L. WILDER
}

Acceptance of an invitation to deliver a lecture in such an eminent and established institution as the Josiah Willard Gibbs Lectureship places on one a responsibility to conform, as well as one's background and talents permit, to the aims and traditions of the series. Fortunately the aims as stated permit a broad range of possible subjects; to wit, the lectures are "to be for a general scientific public on topics in mathematics or in fields closely allied to mathematics." Of course, once an invitation has been extended there is probably no way to control what the invitee says or whether he conforms to the stated aims. And elastic as the aims of the Gibbs Lectureship are, I find on looking over the titles of past lectures, as well as reading the published versions of some, that these aims have been stretched at times to rather extreme limits. Thus the topics have ranged over a broad spectrum from the biographical through biological evolution, astronomy, social sciences, experimental and theoretical physics, mechanics, engineering, sensory prosthesis, genetics, operations research and information theory to pure mathematics. Some of these topics involved extensive applications of mathematics, while others had little or no relation to mathematics. The talks in mathematics have ranged from foundations and philosophy through topology and number theory; only one seems to have been devoted to mathematics as a field, viz., Marshall Stone's lecture 12 years ago on Mathematics and the future of science [1].

My own selection has of course been influenced by my personal interests and limitations, but more strongly by the increasing concern throughout the scientific community with the problems centering about such topics as research and development, basic research versus technology, research versus teaching and the like, not only as affected by public and private support of research, but as represented by congressional investigations and numerous critical articles in both the popular and scientific press. Much of the latter has been characterized by misrepresentation, and in considerable part by misunderstanding. Misrepresentation, especially when deliberate or politically motivated,

\footnotetext{
${ }^{1}$ Except for the addition of section headings and a short bibliography, this is a verbatim copy of the 42nd Josiah Willard Gibbs Lecture delivered before the Annual Meeting of the Society in New Orleans on January 23, 1969; received by the editors April 22, 1969.
} 
we cannot do much about; but misunderstanding we can do something about, and it seems to be the duty of the research scientist to make himself heard if the worst consequences of misunderstanding are to be averted. Some scientists have been unstinting in their devotion of time and effort to this task, through appearances before congressional committees, letters to the press and articles in both scientific and professional journals. In the main, these have been undertaken by representatives of the natural sciences, and while their testimony has undoubtedly benefited mathematics, it has not always recognized or been sympathetic to the special needs of mathematical research; nor has it shown sufficient awareness of the special character of mathematical research. Special thanks are owed to the work of the Committee on Research in the Mathematical Sciences, whose report is currently being published under the auspices of the National Academy of Sciences [2]. Chaired by Professor Lipman Bers, this group has worked over the past three years, without honoraria or other compensation, on behalf of the mathematical community, and I have high hopes that their labors will be instrumental in making both our colleagues in the natural sciences and representatives of government agencies and private industry more appreciative and understanding of the nature and importance of research in mathematics.

Nature of mathematical research. I just mentioned "the special character of mathematical research." It seemed to me that I must elaborate a bit on this, especially since so much of the commentary that has emanated from administrative circles ignores completely the unique character of research in mathematics. In particular, conclusions arrived at in regard to the perennial "research versus teaching" problem, which ignore the differences in fields of research, may be perfectly valid in certain areas while quite the contrary in mathematics.

Relative character of research. Research in any field has a relative character, not only in the manner in which it varies from one field to another, but in its dependence upon other factors such as the time, and the culture which constitutes the environment at any given time. In a culture whose mathematics has ceased to grow, particularly along conceptual lines, research is likely to degenerate into what would be considered elementary problem-solving in another culture. A good example is furnished by the activity of Japanese mathematics during the 17 th and 18 th centuries in the solution of algebraic equations of degrees as high as 3,000 or 4,000 ; work which would certainly not have been considered research by the contemporary European 
mathematicians who were busy developing the foundations of classical analysis. We are all aware of the consequences of the opening up of Japan to European and American trade, a concomitant of which was the diffusion to Japan of Western mathematics. The achievements of Japanese mathematicians since that time are sufficient proof of the fact that it was not due to lack of ability or a potential of great men that had held back Japanese mathematics. ${ }^{2}$

Unique character of mathematical research. Mathematics forms a subculture of the modern scientific culture, and as this subculture has developed into a distinct entity, it has become more preoccupied with mathematics per se and less concerned with other parts of science. Contrariwise, the other scientific subcultures have paid little heed to the lines along which mathematical research has been developing. It is little wonder that the nonscientific community-and this includes virtually all legislators-have no comprehension or appreciation of the nature and importance of research in mathematics. More significant for our present purposes, however, is the fact that the growth of mathematics as a distinct subculture has been accompanied by an expansion of concepts and proof methods which of themselves place mathematical research on a plateau that is simply inaccessible to the general nonmathematical public. Even those who are well enough informed to know that such a thing as mathematical research goes on, have little idea of its nature.

A mathematician can do research without the accouterments of such activities as accompany setting up involved and costly experiments, or in the collection of data or historical materials; this is possibly one of the greatest causes of misunderstanding on the part of the public. Most mathematicians were recently appalled by a statement by a prominent and influential natural scientist regarding the physical environmental circumstances under which one of their own colleagues worked for a short time. That the environment happened to be one such as most up-standing and right-thinking Americans aspire to enjoy was evidently the kernel of the criticism. It may be a virtuous and praiseworthy thing to be a poet in a garret, but not to use public funds to do creative work on the beaches of Waikikieven though the results obtained may be of monumental significance!

When I first read of this, by the way, I was reminded of an incident that occurred years ago during the setting up of a research laboratory under government auspices. A mathematician of consider-

\footnotetext{
${ }^{2}$ For a discussion of the control exerted by the cultural environment on mathematical research, see [3], [4].
} 
able renown listed a cot amongst the items of furniture that he wanted for his office in the laboratory. As might have been expected, the item was questioned; what legitimate role could such an article have in the work of the laboratory? The answer was prompt and direct, to wit: "It is a piece of research apparatus; I do all my best research lying down!" The item was approved.

Early 20th century changes in character of U. S. mathematics. In short, mathematical research has a character of uniqueness which is a natural result of the extensive development of mathematics as a distinct subculture. This development is essentially a 20th century phenomenon, and I believe that American mathematics played a major role in it. In his Gibbs lecture [5], E. B. Wilson remarked that those American mathematicians who went to Germany for their graduate education, came under the influence of men with a broad knowledge of applied mathematics, such as Felix Klein, who was at the time "emphasizing the need in Germany of a greater attention to applied mathematics. Nevertheless, they "came back to this country with a determination to promote only pure mathematics." Wilson did not go into the reasons for this, but it poses an interesting problem in the historical sociology of mathematics. It is possible that the undergraduate backgrounds of these men were in no way as strong in general scientific matters as were those of their European counterparts, who although they generally wrote dissertations in pure mathematics, in their subsequent careers retained their interests in the applications of mathematics to the natural sciences. Incidentally, Willard Gibbs was an exception in that he had studied with Weierstrass and had an appreciation of pure mathematics, but he never lost his interest in applied mathematics.

The growth of interest in pure mathematics in this country has certainly been greatly instrumental in the course that mathematical research has taken over the past half century. Along with the influence of European groups such as the Bourbaki group in France and the Polish school of mathematics, the great strides taken in research in pure mathematics have brought to full flower the seeds which had been sown during the preceding century by such men as Riemann, Grassmann, Weierstrass, Cantor and others who contributed new patterns of thinking in mathematics.

Subsequent course of research; increasing abstraction. There is no question but that this preoccupation with pure mathematics caused some concern within mathematical circles, particularly up to twenty years ago. Many feared that mathematics was turning from 
the modern concept of science as a tool for the understanding and control of natural forces, to the Greek ideal of pure intellectual curiosity.

Nevertheless, two great benefits resulted: In the first place, mathematics became unified or, to put it another way, mathematics achieved cultural identity. From being merely a tool for other sciences to exploit-the "language of science," as some put it-mathematics became a science in its own right. And secondly, there resulted the realization of the great power of abstract mathematics with its emphasis upon the study of structures and relations. The study of formal structures actually started in the 19th century, and it is possible that fascination with this aspect of mathematics also had something to do with the turning from the classical types of applied mathematics to the so-called pure mathematics by the pioneers of modern American mathematics. At any rate, from a present-day standpoint we can see that these developments, rather than representing a wrong direction in mathematics, were a natural trend preparing for applications hitherto undreamed of.

New applications and wider cultural influence. Set theory and measure theory underlie modern probability theory, which in turn is one of the most important tools for modern physics; abstract logic contributes to theories of computation and other fields; and even the theory of distributions, introduced by Laurent Schwartz, is developing into a powerful tool for probability, physics, and general systems theory. ${ }^{3}$ It is a remarkable confirmation of the cultural forces influential in the evolution of mathematics that the researches in pure mathematics are providing more and more of the methodological and conceptual tools required by modern science.

Consolidation. About 25 years ago, mathematics seemed to be breaking up into a host of specialities, whose various proponents spoke different languages, and which threatened to become distinct subcultures of mathematics. Although this condition still exists, today the trend seems to be definitely in the opposite direction. Some of the most striking results of recent years, such as the solution of the general index problem by Atiyah and Singer, ${ }^{4}$ have been achieved by

8 Under auspices of the Air Force Office of Scientific Research, a symposium was held in 1966 at the Fall meeting of SIAM on "The Applications of Generalized Functions to Systems Theory." Some of the papers presented may be found in the July, 1967, SIAM Journal of Applied Mathematics.

- It was a happy coincidence that the Chauvenet Prize of the AMS was awarded for this result on the afternoon of the day on which this lecture was given. 
using results from analysis, geometry, topology and algebra, and can hardly be ascribed to any one field of mathematics. And that this would happen could have been predicted by anyone familiar with the forces underlying the evolution of mathematical concepts.

Before the classical types of analysis, algebra and geometry could be consolidated, it was necessary to make extensive generalizations in these fields through the study of the conceptual structures underlying them. Once this had been accomplished, diffusion from one field to another commenced and consolidation on the grand scale could occur. Put succinctly, what has occurred (and is still occurring), is really an operation of what might be called the Law of Consolidation; specifically, that wherever greater efficiency will result, consolidation will ultimately occur; and the consolidated entity will have attributes that none of the original individual entities had. Indeed, this seems to be a general law of nature. Thus, among living entities, it is exemplified by the consolidation of cells to form new living structures having properties unattainable by the elements entering into their makeup. In chemistry, examples abound; aspirin has properties possessed by none of its component molecules of carbon, hydrogen and oxygen. In sociology, we see congregations of individuals forming political or social consolidations which can achieve a wide variety of tasks impossible for the individual. In economics, mergers occur between related industries and, recently, even nonrelated industries. In fact, everywhere in nature and society we observe this trend toward consolidation. The result of the operation of the Law of Consolidation in mathematics is the power to solve problems that have hitherto defied solution. Research in mathematics has become more and more a search for structures and relations, representative of conceptual frames over the whole broad spectrum of mathematics. Structures which in effect consolidate two or more branches of mathematics are likely to be the most effective in their mathematical and scientific fruitfulness.

Growth trends. One of the most salient features of research in mathematics over the past century is its remarkable growth in volume. Comparison of the program of this meeting of the Society with those of a few years ago reveals striking evidence of this growth.

Accelerated growth is common to all science, though perhaps not as much as in mathematics. In an article first published 12 years ago and more recently reprinted in a volume of essays on the sociology of science [6], Derek J. Price presented statistics based on such items as numbers of articles in abstracting journals, output of degree- 
granting institutions, and annual expenditures for scientific research, from which one might conclude that the growth of science since 1700 has been exponential, and that the time required for doubling has been 10-15 years. However, since a further exponential growth for 250 years would give about 100 scientists for every man, woman and child in the world today, it is evident that a saturation level must be in the offing. He concluded that the growth curve is similar to that of a colony of bacteria, and estimated that the growth of science will have approximated the saturation point about 40-60 years from now.

By way of a quick check to see if similar conclusions might hold for mathematics, I noticed that the number of abstracts in Mathematical Reviews has been doubling every 8 or 10 years since 1940; also the Young-Jewett Survey indicates doubling in the output of $\mathrm{Ph} . \mathrm{D}$. 's at 8 and 5 year intervals since $1954 .^{5} \mathrm{I}$ have not, however, tried to establish any quantitative estimates of the growth of mathematical research over the past century or longer. It appears not unlikely, in view of manpower and financial limitations, that in the long run the growth of research in mathematics may be found to approximate the traditional growth curve. However, we cannot expect mathematics to follow the same curve as zoology, for instance. Presumably the factors influencing the growth of different fields vary considerably, and there is reason to believe that the growth of mathematics is influenced by internal forces more than are sciences which depend mainly upon external factors, such as natural phenomena. The functional role of a field is a major factor in controlling its growth.

In a recent article [7], Kenneth Pitzer stated that "further growth brings less able people into research"; and that "it is quite clear that the contribution of those who are added by further growth in research will be less, per person then (sic) the present average." As Dr. Pitzer is a chemist, perhaps his opinions were influenced by conditions in chemistry. I am convinced that they do not hold of mathematics. For a long time I have felt that we attract to mathematics only a small fraction of the potentially first rate mathematicians who pass through our classes. And I believe the reason for this is chiefly the paucity of creative teaching. We spend too much time teaching the student, with the result that he spends too little time learning and exercising his own potential. I believe it was Plutarch

\footnotetext{
${ }^{5}$ From preliminary reports. This survey is being conducted by the CBMS under a grant from the Ford Foundation.
} 
who stated that "The mind is not a vessel to be filled, but a fire to be kindled."

But to come back to the growth trends: Mathematics is like an industry, growing larger and more complex all the time. And the more complex it becomes, the greater are the demands put on those charged with its development to introduce greater consolidation and simplification. A corollary of the intensive and rapid changes going on in mathematical research today is the necessity for keeping up to date. This is not peculiar to mathematics, but seems to be part of a general phenomenon which pervades modern society. The rapidly changing and evolutionary character of technology puts the same responsibility on the business executive to familiarize himself with new concepts as it does on the scientist. More and more frequently one reads of business executives retiring at ages which would have been considered unjustifiably low a few years ago; and many of these quite frankly state that they can no longer keep up with the pace of changing technology but must defer to the younger men whose outlooks are unhampered by outworn concepts. Perhaps the scientist should consider himself fortunate that he can take advantage of various forms of subsidized leaves in order to keep himself up to date. Some such arrangements are appearing in the industrial world as in the one and two week seminars for business executives now often provided by the universities.

One kind of research which seems to have fallen into neglect, in this country at least, and which I feel should be rejuvenated, is history of mathematics. I think there are three principal reasons for its neglect: (1) American historians have been interested principally in the history of elementary mathematics; there were a few notable exceptions such as J. L. Coolidge and E. T. Bell-but neither of these was primarily a historian and presumably not, therefore, likely to create a following. (2) As mathematics matured in this country, historical writing came to be looked upon as more expository than creative and, too, the activity in extending the frontiers of mathematics was engaging all available manpower. (3) The history of mathematics gradually became absorbed, under the departmental system in vogue in our universities, into departments of the history of science. There is nothing inherently wrong with this development, but unfortunately capability of doing justice to the history of modern mathematics requires a knowledge of the subject on a par with that usually expected of the regular Ph.D. candidate in mathematics. I learned recently of the case of a man who had apparently prepared for the Ph.D. in mathematics, but who became so interested in a topic in the history 
of modern mathematics that he wished to write his thesis on it. However, it was necessary for him to transfer to the history of science department in his institution and fulfill its requirements in order to do this. I hope that this situation may change in the future, especially since the time is past due when systematic records of some of the developments in modern mathematics can be adequately treated. Already if you ask two or more older mathematicians for their opinions of the circumstances surrounding the innovation of important mathematical concepts soon after the turn of the century, you will find that they not only disagree regarding the details, but some will probably be unable to make any recall. I might note, in passing, that research in the history of mathematics is quite active in Russia today.

Social implications of research. Now what are the implications for society of all this research activity? I have already mentioned the effects of changes in technology, upon which mathematical research has had both a direct and indirect influence. Most immediate, perhaps, are the effects on the educational complex. I have referred to research as an instrument of evolution, and obviously the evolutionary process depends upon each generation of researchers training the next. One of the greatest obligations of an academic mathematician is "to pass on the torch," as the saying goes. Moreover, since the choice of mathematics as a profession is usually dependent upon its being made attractive to the student, it is clearly the duty of the teacher to see that this is done.

The effect of modern research on teaching of mathematics has been salutary. Students who are just beginning graduate work are enabled to assimilate concepts that most of us who belong to older generations have difficulty digesting. I am reminded of a letter that I received from an older colleague when back in 1934 I extolled the advantages of consolidating set-theoretic and algebraic methods in topology. He asked how could I expect a man of his age to assimilate the concepts of a part of mathematics with which he was totally unfamiliar? However, once this consolidation had been effected, it presented no such problem to the younger men who commenced their study of topology in the already consolidated form.

Not only have the courses in the undergraduate colleges also been affected, but the inevitable up-dating of elementary and secondary curricula is being accomplished. For a long time the university mathematicians maintained a "hands off" attitude toward the mathematical teaching in the secondary schools, and those of us of the 
older generations remember how years ago, in desperation albeit with reluctance, we introduced courses into the college curricula which were repetitions of what the student supposedly had learned in the high schools. It would be redundant for me to rehearse here the reasons for and the details of the recent "revolution" in secondary curricula (which is still going on), except to record that this is all, in the final analysis, the result of mathematical research going back to the work of Abel, Galois and others. For with these gentlemen, mathematics began to recognize the importance of structures, which have played such a central role in the generalization and consolidation of modern mathematics and its applications.

Mathematics is not alone in this up-dating process, of course; the natural sciences are being similarly modernized. I would not venture so far as to predict that consolidation between all the sciences will ever be effected; but equally I would not say it is impossible. Presentday research in all sciences shows increasing consolidation, and we could yet see the return of the universal scientist of over a century ago-a breed which vanished with the onset of specialization. Research is itself an instrument not only of the evolution of mathematics, but contributes to the process of consolidation both within mathematics and externally to the whole of science.

The relations between research and teaching have a number of aspects, such as: (1) The effect of the results of research on curricula; (2) the much publicized "conflict" between research and teaching; (3) the influence on his teaching of one who is a researcher; and (4) the special case of the relations between a teacher and a student doing research under his direction.

(1) To one acquainted with the curriculum changes that have occurred during the past twenty years, little further need be said concerning the effects of research on teaching, so far as the curriculum is concerned. (2) But so much has been spoken and written on the "conflict" between teaching and research that I am going to comment on aspects of it that I think should be emphasized over and over. One of these is the popular folklore that a good research man cannot be a good teacher. I do not know how this folklore started; certainly there have been cases of renowned researchers in every field, who from lack of interest, personality defects, neglect of teaching duties, or other reasons, were failures as teachers, and with the help of a little publicity such cases are easily provocative of the growth of folklore. Since profound interest in a subject usually results in a desire to communicate this interest, I have never doubted that, normally, research interests should foster good teaching. 
Why did research come to be so much more highly regarded than teaching, anyway? There have been instances where renown has ensued from the excellence of a person's teaching, of course. But I refer particularly to the emphasis placed on achievement in research when a university teacher's qualifications for promotion are under consideration. What is the origin of this? I am not so naive as to believe that a department chairman is acting only upon a belief that a good research man is ipso facto a good teacher. He is also thinking of the reputation of his department in the academic world. But this is not the origin of the practice. As in the case of most of our beliefs and actions, we have to search more deeply for the origin.

It probably goes back to the observation that all great innovations seem to be the work of exceptional individuals. It is a social fact that the exceptional individual, the one who can do something better than anyone else, or who creates ideas or gadgets that influence our thinking and living, comes to be either highly regarded or notorious. Even an unusually successful thief achieves fame and of ten becomes a folk hero. It seems to be a corollary that creativity, no matter on how modest a scale or how antisocial for that matter, merits recognition. Of course the origin of a practice and what it later develops into are not the same. But I think it unquestionable that from the (justifiable) acclaim of men of the calibre of Cauchy, Abel, Gauss, Riemann and the like, who exerted an unmistakable influence on the development of mathematics, has come the current emphasis on research ability. More contemporary factors enter too, such as the flocking of students to those institutions which have been most successful in corralling the most renowned research men.

I confess to some misgivings when I first witnessed the turning of young men from teaching by the influx of government and private grants for research. But apparently most of these people later develop into mature mathematicians with a natural interest in imparting the love of mathematics to others. But while interest in research may be accompanied by an interest in stimulating teaching, it does not follow that possession of the $\mathrm{Ph} . \mathrm{D}$. degree is a guarantee of competence. It well behooves the department chairman not to rely too much upon the degree as a criterion for admittance to his staff. There are many ways other than by research activity, whereby interest in a subject can be so well nourished as to guarantee stimulating teaching, especially on the undergraduate level. In a field that is not undergoing development, but has become a fixed technology, so to speak, there seems little point to keeping up a pretence of "research." This is one of the reasons why I believe that to discuss the research versus 
teaching problem without reference to the particular field-and I have often heard college administrators do this-is likely to be of little value. I suspect that there may be subjects in the universities where research is encouraged mostly for prestige purposes and in which the value thereof is nowhere comparable to that for the sciences and particularly mathematics.

As I have already hinted, these remarks are intended to apply to the undergraduate area, since work with graduate students should hardly be undertaken by anyone without a research interest. The reasons for this are obvious to an audience of this kind; research is not learned from books, but by doing research under the eye of the experienced master. I do want to make one observation in this connection, however. We sometimes spend hours in - usually fruitlessdiscussion concerning what is good research or what is important research. When a long-standing problem is solved, and the way to new investigations opened up, there is no question. But how much run-ofthe-mill research can be called "good"? I think that to use only such criteria as, say, relevance for some application outside mathematics, or even significance to the development of mathematics itself, is sometimes a mistake. I have in mind, for instance, research that is so adaptable to the student's capabilities as to allow him to participate in it early in his career. I believe that such research is of great importance. I have always felt that a student should start doing research as early as possible. Mathematics, like music, profits by cultivation in the very young, and anyone who uncovers a previously undeveloped field of mathematics that permits the student of little background to do research in it, is probably providing as great a service to mathematics as one whose research has obvious significance for either applications or for the main lines along which mathematics is being developed at the time.

After all, the value of research is also a relative thing. I can recall that while teaching a course in graph theory 30 or 35 years ago, I recognized that far from being the dead field that it was regarded to be at the time, it offered great potential for research by a student without a great deal of background in classical mathematics. However, the recent resurgence of research in graph theory was apparently not due to any such consideration, but to the discovery that it had applications to problems in both the natural and social sciences-a fact that I suspect Cayley knew but had no time to pursue beyond some elementary work on chemical bonds.

Three years ago an editorial in Chemical and Engineering News [8] stated: "A relatively small portion of the federal budget for Research 
and Development can be said today to be closely related to education - through the investment of modest sums, quite large numbers of good individual research problems in chemistry can be made possible in our universities. Such projects would have as a part of their function the training of graduate students." This seems to be in line with what I have just been saying.

So far as industrial work is concerned, training through the doctorate appears, at least in the cases that have come to my attention, to be an asset of considerable value. Moreover, the research need not always be in applied mathematics, except of course in cases where the student is going into a specialty such as engineering research, computing, actuarial science or other technical profession. I have observed among my own students, a number of whom have entered industry, that research even in the most abstract mathematics, affords an experience which seems to endow one with a capacity to think along broad lines not always possible for the more technically trained person.

Government support of research. A major aspect of the social setting of mathematics in this country today is the relations with the government. The tremendous growth in research and the reestablishment of liaison between university mathematicians and secondary school teachers that have occurred since World War II were chiefly made possible by federal support, both financial and moral. Most remarkable of all in these developments was the role played by defense agencies, who, surprisingly enough, recognized early the importance of basic, and particularly mathematical research. The first grants in mathematics, I believe, were made by the Office of Naval Research.

But as many forewarned, there would come a day of reckoning. I think two of the earliest signs of erosion in the blissful system of awards and grants were (1) retrenchment in defense agencies to the support only of mission-oriented research, resulting in bureaucratic judgment as to what research is significant to the granting agency; and (2) imposition by the National Science Foundation of judgments which resulted in raising the question of freedom of research; the fact that these may have been inspired by congressional pressure does not lessen their significance. During the past few years congressional inquiries into the nature of research and in particular the justification for spending the tax payer's money on basic research have become common. Since the average layman has not the least inkling of the nature of scientific research, and considers that a dollar spent for 
research should produce several dollars worth of better toothpastes, television sets and other technological wonders, the result has been a field day for the politician bent on reducing the budget for scientific research. It is all too easy to look through the titles of research proposals which have been awarded grants, particularly in basic research, and to hold them up to ridicule by a noncomprehending public. The award may be a mere pittance in comparison with the billions spent for easier to understand military and space projects.

Such contrasts are to be expected when one considers how poorly informed concerning basic research are both the electorate and their representatives. In spite of this, however, the over-all influence of government grants has been beneficial, I believe, though we must be ever on our guard to see that decisions regarding what research is important enough to warrant support are not left entirely in the hands of nonscientists. Social decisions are not made because they are reasonable, as a rule. The mathematician, accustomed as he is to approach every matter from the standpoint of reason, usually does not take into account that Society is stupid, not reasonable. Examples abound of beliefs whose hold on a culture is so firm that they continue to live on for centuries after they have been exposed as fallacies. No amount of explanation can change the popular idea of science as an agency for the production of more useful gadgets, and that it is practiced by men in long white coats working in labs filled with test tubes. Consequently mathematics in the popular mind is not a science, because mathematicians do not wear long white coats and use test tubes in their work. Failure to take this into account is unquestionably one of the difficulties underlying problems encountered in the innovation of modern curricula in the schools as well as in solicitation of financial aid from government, private industry and even, let's face it, college administrators.

Mathematics and mathematical research are an integral part of modern society; their relations are those of part to whole. One can perhaps understand better the implications that mathematical research has for Society if he considers what would happen if all research in mathematics were to cease. What could cause such an event? In the first place, the motives for doing research, which activate the individual mathematician, would have to disappear. These motives are complex, and may be of one or several kinds such as (1) the inner compulsion to do research which is associated with the fascination for delving into the unknown; (2) advancement in the profession in either status or salary, or both; (3) participation in the 
directing of doctoral work; (4) competitive factors-for many this is part of the fun of doing research. Of these, only one, namely the love of doing research, comes from within the individual (although even it is usually originally due to an external factor in the environment, such as a stimulating teacher). And this inner motivation could easily be killed either by creating a poor atmosphere for research or by using up all a mathematician's energy in other ways.

Thus, the first Gibbs lecturer remarked in an autobiographical work copyrighted in 1922 [9] that his early years of teaching at Columbia were fraught with difficulties. "When the professor of engineering died, in the summer of 1891, a part of his work, theory of heat and dynamics, was assigned to me. The professor of dynamics died a little later, and his work also was transferred to me. I was to carry the additional load of lecture-room work temporarily, but was relieved from it, in part only, after several years. As a reward my title was advanced to adjunct professor, with an advance of salary to $\$ 2500$ per annum. But in return for this royal salary I had to lecture three to four hours each forenoon, and help in the electrical laboratory instruction in the afternoons. While this pedagogic load was on my back scientific research could not be seriously thought of. My young colleagues in other colleges were similarly situated. This overloading of young scientists with pedagogic work threatened to stunt, and often did stunt, their growth and also the growth of the rising American university." Circumstances such as these have been largely eliminated, I believe. However, they illustrate one of the ways in which the research incentive could be killed.

Since mathematicians do not live in a vacuum, but are affected by cultural ties as much as any other subculture, the demand for research would also have to cease. Another way of stating this is to say that Society itself would have to be the prime mover in cessation of research, in that it would so act as to remove the individual's motivation for research. Consequently we should examine the function of mathematical research from Society's standpoint.

The main function is, unquestionably, as a basic instrument in providing the conceptual tools which every science calls for at certain stages in its evolution. The natural sciences and engineering have up to now made the greatest demands upon mathematical research, but the behavioral and social sciences are beginning to look to mathematics, and it is frequently some of the newest concepts that have resulted from mathematical research which they find best suited to their needs. Without belaboring the point, I think it will be clear that 
for research in mathematics to cease, scientific research in general would have to end-a circumstance which has been devoutly hoped for in some quarters during the past quarter of a century.

Pursuing the matter a little further reveals that in the eyes of the public, the main social functions of scientific research are to serve the needs of technology, and consequently it seems that cessation of mathematical research would be contingent on the stoppage of technological progress which, we must observe, is the very basis of cultural evolution.

This may seem indulgence in dreaming, but let us not forget that it has happened in the past, and could happen again. The ChineseJapanese cultures, and the post-Hellenic Western cultures of the Dark Ages furnish examples. Both were characterized by political unity as well as by freedom from threat of aggression without. It leads one to ask what would be the effect of eventual establishment of a world community, with that peaceful utopia which many of us hope for? Would there be a danger that technological progress, and hence scientific research, might be one of the victims of the absence of space competition and warfare?

I hope you will pardon this seemingly idle conjecturing. But perhaps it gives some substance to the assertion that mathematics and mathematical research form an indispensable feature of modern Society. Without it, research in basic science would be impossible and, along with it, advance in technology. In short, mathematical research is a sine qua non for continuing progress in the evolution of modern Society.

\section{BIBLIOGRAPHY}

1. M. H. Stone, Mathematics and the future of science, Bull. Amer. Math. Soc. 63 (1957), 61-76.

2. The mathematical sciences: $A$ report, Pub. 1681, Nat. Acad. Sci. U.S.A., 1968.

3. R. L. Wilder, The cultural basis of mathematics, Proc. Internat. Congr. Math. 1950, vol. 1, pp. 258-271, Amer. Math. Soc., Providence, R.I., 1952.

4. - Evolution of mathematical concepts, Wiley, New York, 1968.

5. E. B. Wilson, Reminiscences of Gibbs by a student and colleague, Bull. Amer. Math. Soc. 37 (1931), 401-416.

6. D. J. Price, "The exponential curve of science" in The sociology of science, edited by B. Barber and W. Hirsch, Free Press, Glencoe, Ill., 1962, pp. 516-524.

7. K. S. Pitzer, Hou much research? Science 157 (1967), 779-781.

8. R. L. Kenyon, The purposes of research, Chem. Engr. News, June 21, 1965, p. 7.

9. M. Pupin, From immigrant to inventor, Charles Scribner's Sons, New York, 1926, p. 291.

University of Michigan, Ann Arbor, Michigan 48104 